\title{
Retrospect and Prospect of the Supplementary Policies on Rural Teachers in China in the Past 40 Years Since Reform and Opening-up
}

\author{
Jiao Zeng \\ South China Business College \\ Guangdong University of Foreign Studies \\ Guangzhou, China 510545
}

\author{
Xiujun Wang \\ South China Business College \\ Guangdong University of Foreign Studies \\ Guangzhou, China 510545
}

\begin{abstract}
Since the reform and opening up, the supplement of rural teachers in China has gone through three stages, namely, the stage of private probation teachers as the main source, the stage of distribution of secondary normal university students as the main source, and the stage of diversification of the combination of open recruitment and examination and special projects. At present, governments at all levels have made various attempts within the existing policy framework, and the supplement of rural teacher team has scored some results. However, there currently are still many difficulties in supplementing rural teachers because the professional attractiveness and competitiveness of rural teachers are low and the number and speed of supplementing teachers are less than the number and speed of loss. As a result, the government has constantly broadened the supplementary channels for rural teachers, issued policies and taken measures to keep the two paths of supplementing teachers and retaining teachers in one time.
\end{abstract}

Keywords-reform and opening up; rural teachers; supplementary policies; open recruitment

\section{INTRODUCTION}

Rural teachers are an important guarantee for the development of rural schools, and the supplement of rural teachers is the most important factor in the rural educational investment. Since the reform and opening up, rural education in China has rapidly developed and constantly changed, which has made an important contribution to consolidating the achievements of compulsory education in China that have attracted worldwide attention. Our country has always attached great importance to rural education. The administrative departments at all levels have made clear provisions on the supplement of rural teachers in different historical periods. In general, the number of teachers in rural areas is expanding and the quality is improving. However, because of the longstanding dual development system of urban and rural areas in China, rural schools, especially those in remote areas, have been facing serious issues of teacher shortage and loss. Therefore, from the end of 1990s to the beginning of the 21st century, the state successively issued a series of documents such as the Action Plan for the Revitalization of Education for the 21 st Century, the Decision on Deepening the Reform of
Education and Promoting Quality-Oriented Education in an All-round Way, the Decision of the State Council on the Reform and Development of Basic Education, and the Notice of the General Office of the State Council on Improving the Management System of Rural Compulsory and the Decision of the State Council on Further Strengthening Rural Education Work and so on, and the "Special Post Plan for School Teachers at the Stage of Rural Compulsory Education" and the free education method for normal school students. Excellent teachers and graduates have been guided and encouraged to teach in rural areas by offering multiple preferential policies such as compilation, fund guarantee, professional titles, and qualifications of teachers, wage preference, fixed directional distribution and supporting education and so on. These measures and approaches have largely alleviated the issue of insufficient number and poor quality of teachers in rural schools. However, there are still outstanding issues in rural schools in remote mountainous areas and poor areas such as weak attractiveness of rural teachers' posts, non-smooth supplementary channels, insufficient quality resources, unreasonable structure and poor overall quality and so on, which hinders the overall sustainable and healthy development of rural education. With the 2010 Outline of the National Medium-and Long-term Educational Reform and Development Plan clearly put forward the "Innovation of Rural Teacher Supplementary Mechanism" and the launch of the Rural Teacher Support Plan (2015-2020) in 2015, the rural teacher supplementary mechanism has been improved, effective policy services suited to the characteristics of rural schools in weak areas have been provided, and form a team of rural teachers who can go to rural areas, stay in there and teach well there, which are the realistic problems that need to be urgently solved at present.

\section{The ChANGING COURSE OF SUPPLEMENTARY POLICIES ON RURALTEACHERS IN THE PAST 40 YEARS SinCE REFORM AND OPENING-UP}

\section{A. The Stage of Private Probation Teachers as the Main} Source

In the early period of reform and opening up, the shortage of rural teachers' resources was very common. In order to 
relieve the extreme urgency, schools, brigades and primitive communes all over the country could choose and hire probation teachers. Although the shortage of rural teachers was alleviated to a certain extent, the quality was uneven and the management was relatively confused. It was not until January 1978, when the Opinions on Strengthening the Management of Teachers in Primary and Secondary Schools was issued, that the permission and procedures of private teachers' supplement were established. The document put forward that "the management of private teachers should be strengthened, and when selecting private teachers, the county educational administrative departments should make overall planning according to the actual demands of the development of educational undertakings. Private teachers' appointment should be based on the principle of appointing people on their merits and equal stressing on integrity and ability, and nominated by schools and brigades, recommended by primitive communes, examined and approved by county educational administrative departments, and then issued appointment certificates." At that time, Hebei Province did a better job. According to the procedures and standards, private teachers were examined that qualified teachers were issued with qualified certificates and unqualified but qualified teaching workers who were issued with probation certificates. They were examined after the improvement of their cultural and professional skills, qualified teachers were issued with qualified certificates, and those who were still unqualified were completely dismissed. Those who are capable of teaching would be professional training. Through a series of policies and measures, a large number of private teachers have passed the examination and served as full-time teachers in rural schools, which has strengthened the team of rural teachers and promoted the development of rural education.

\section{B. The Stage of Secondary Normal University Students Distribution as the Main Source}

With the development of college and technical secondary school education, a large number of qualified teachers have been trained for the country. By the mid and late 1980s, the supplementary sources of rural teachers have begun to change, and the supplement system of probation teachers have begun to collapse. Instead, the normal students of colleges and technical secondary schools after graduation have been allocated to rural schools to teach according to needs.

In May 1983, the Notice on Several Issues on Strengthening and Reforming Rural School Education pointed out that "relevant colleges and universities should train and transport professional personnel for the countryside, train teachers for various types of schools in the countryside" and "allocate a certain proportion of graduates from colleges and secondary specialized schools to teach in various types of schools in the countryside". However, in this period, there was a shortage of talents in all walks of life, so few graduates could be allocated to teach in rural schools. Therefore, the policy had not been implemented in place where it should be, and private probation teachers were still in a transitional stage. Until the end of the 1980s, the scale of normal education culture in colleges and technical secondary schools has been expanded and graduates have gradually increased. They have begun to replace private probation teachers and become an important supplementary source for rural teachers.

With the deepening development of reform and opening up, the policy of "national unified enrollment and national unified allocation" with a strong brand of planned economy began to change in the early 1990s, and gradually established a teacher recruitment assessment system characterized by market economy. But until the end of the 20th century, the number of graduates of normal colleges and schools was small before the increased enrollment of higher education in China, and the supply was less than the demand. Therefore, the teacher entrance examination and enrollment system in most rural areas was not strictly implemented and the employment conditions were relatively relaxed.

\section{The Stage of Diversification of the Combination of Open Recruitment and Examination and Special Projects}

Entering the 21st century, China's higher education has begun to expand enrollment, normal education has continued to reform, the number of normal graduates has increased year by year, and the teacher recruitment and examination system, which has been explored for many years, has begun to flourish everywhere. All elementary and secondary schools around the country have implemented the teacher recruitment policy of "admission of public servant after passing examinations". In 2005, the Ministry of Personnel promulgated the Interim Provisions on Public Recruitment of Personnel in Public Institutions, which required public institutions to carry out public recruitment of new personnel except in exceptional circumstances, including public schools at all levels. So far, the supplementary source of rural teachers has turned to the unified recruitment of examiners.

However, as far as the conditions of rural areas are concerned, it is still unable to meet the demands of teachers in rural schools only by means of open recruitment. In order to attract more outstanding talents to teach in the countryside, enrich the team of rural teachers and improve the quality of rural teachers, the state has formulated and promulgated a number of special policies to explore new channels for the supplement of rural teachers. There are four major projects implemented successively, namely, the "three supports and one assistance plan" in February 2006, in which supporting education to remote areas is an important part; the "special post teachers plan" in May of the same year; the "free normal students plan" in 2007; and the "master teachers plan" in 2010.

Through the joint efforts and innovations of the central government and local governments, multiple project attempts have been made to deliver a large number of new teachers to schools in rural areas. As a result, the supplement of rural teachers has achieved some results. However, from the development course of the past ten years, the number of rural teachers is still insufficient, the supplement of qualified teachers is still difficult, the loss of teachers is serious and the aggravation of the aging trend mean that the diversified supplementary policy combined with public entrance examination and enrollment and special projects has not yet achieved the desired results. There are still numerous realistic plights when it comes to establishing a stable and qualified 
rural teacher team, and it is still necessary to further explore the supplementary sources of rural teachers.

\section{ACHIEVEMENTS AND PROBLEMS OF SUPPLEMENTARY Policy CONSTRUCTION FOR RURAL TEACHERS IN THE PASt 40 YEARS SINCE REFORM AND OPENING-UP}

\section{A. Main Achievements}

Over the past 40 years since reform and opening up, China's rural teacher supplementary policy has been gradually developed and continuously improved, which provides relatively stable teacher resources for education in rural areas and promotes the development of education in rural areas, thus achieving remarkable achievements. Meanwhile, this policy also has further consolidated the universal achievements of nine-year compulsory education and increased the scale of existing school students. The conditions for running schools have been further improved, the gap between urban and rural areas has been gradually narrowed, and the balance of resource allocation has been improved.

According to statistics, there were 10.6946 million fulltime teachers in general primary and secondary schools in 2013, of which 76.22737 million were in rural areas (including, rural-urban interface, townships and villages), accounting for $71.31 \%$ of the total number of full-time teachers in general primary and secondary schools in China. According to official data from the Ministry of Education, the total number of rural teachers in China was 3.3 million in 2015. [1]

As of 2016, there were 230,000 schools in the compulsory educational stage, 98,000 teaching points and 140 million students in the compulsory educational stage. Among them, there were 178,000 general primary schools and 17.525 million primary students were enrolled nationwide; there were 52,000 junior middle schools and 14.872 million junior middle students were enrolled nationwide. The enrollment rate of primary school graduates in China is $98.7 \%$, and the gross enrollment rate in junior middle school stage is $104 \%$. [2]

China's rural areas have vast territory and abundant resources with numerous rural populations. School education in rural areas is related to the quality of Chinese basic education as a whole. Different supplementary policies for rural teachers have been adopted in different times to effectively guarantee the qualified teachers in rural schools effectively promote the development of education in rural areas and further promote the development of basic educational undertakings in China.

Over the past 40 years, rural teachers' supplementary channels have developed from single to multiple, and the scope of supplementation has been expanding. Since the 1990s, the state has issued a series of policies, which constitute a pluralistic supplementary channel with open entrance examination and enrollment as the main supplement, special post teachers and free normal students as the supplement. At the same time, in order to further expand the supplementary channels of rural teachers, the state has formulated supplementary policies such as supporting educations in the countryside, three-support and one-assistance and so on. Some provinces and municipalities have formulated some local supplementary policies according to the specific conditions of their regions such as Gansu Province's plan of entering villages and communities, Guangxi Zhuang Autonomous Region's general teacher plan and so on, which make our country rural teachers' supplementary channels present multiple characteristics.

\section{B. Existing Problems}

Over the past decade, China's educational business has developed rapidly, but the development of rural education is still lagging behind that of urban development, especially there are numerous difficulties in the supplement of rural teachers.

The diversified supplementary policy has not made the supplement of rural teachers go out from under, and the number of public entrance examination and enrollment applicants is less, even less than the number of people to be hired; the newly-added special post teacher turnover rate is higher; the total number of free normal students is too low and difficult to send. [3] As a result, many districts and schools have to use a large number probation teachers and reemployed teachers. In some schools, the number of probation teachers has even reached 50\%. [4] With the aging of rural teacher teams, 10 years later, the current stable registered teachers have basically reached retirement age, and then rural schools will face supplementary difficulties.

Conditions in rural area are difficult and unattractive. With the establishment of the open entrance examination and enrollment system and the launch of diversified projects, the supplementary sources and scope of rural teachers are constantly expanding. Normal students, non-normal students, freshmen and former students all can sign up for a post as a village teacher as long as the educational backgrounds and ages meet the prescribed conditions. In theory, when the demand for rural teachers has not changed greatly, the scope of supplementary sources has expanded, which means that teacher resources have not lacked and can even be hired based on merit. However, this is not the case. It is impossible to fill the planned quota every year. In remote places where people are missing, the more difficult it is to recruit. Therefore, it can be seen that the attractiveness of rural teacher post is seriously inadequate. If the admittance threshold is lowered again, it will lead to the lower overall quality of the rural teachers, which will affect the quality of education.

In 2010, the number of rural teachers in China was about 5 million. In 2015, the number of rural teachers in China fell to more than 3.3 million, representing the rate of loss of rural teachers about $35 \%$ in the past five years. [5] It can be seen that the serious loss of rural teachers is also a major practical problem. Some young teachers have a very high turnover rate within three years of employment. Even some new recruits have just arrived at rural schools and proposed to leave. Some studies show that the average loss rate of newly-added teachers in rural areas in recent years is about $20 \%$. [6]

\section{RURAl TEACHERS' SUPPLEMENTARY POLICY OUTLOOK}

Although the rural teacher supplementary policy has not achieved the expected results for many years, the government attaches as always importance to the supplementary problem 
of rural teachers, attaches importance to the construction of rural teacher teams and attaches importance to rural education. It also is committed to running an education that is satisfactory for the people. In February 2018, the Ministry of Education and other four departments jointly issued the Teacher Education Revitalization Action Plan (2018-2022), which defined the revitalization goals and the top ten revitalization actions in the next five years. At present, the professional certification of normal teachers has been rolled out. The Ministry of Education has set up a committee of certification experts, held a deployment meeting, and defined the implementation plan. All authorities from place to place are actively promoting, which will further raise the threshold of teacher education and improve the quality of teacher training.

To vigorously revitalize teacher education, the ability of teachers' professional quality must be constantly improved. According to the Opinions, a teacher education system with Chinese characteristics with normal colleges and schools as the main body and the participation of high-level non-teaching colleges and schools will be established, and the "trinity" of local governments, institutions of higher learning, and primary and secondary schools will be promoted to cultivate students and create high-quality compound teachers with solid disciplinary knowledge, outstanding ability and profound education feelings. What is striking is that the "free normal students" have been upgraded to "public fee students", and the period of performance service has been adjusted from 10 years to 6 years to attract more outstanding students who are interested in teaching to enter the normal specialty.

Recently, teachers from "ten thousand teachers supporting education for assisting Tibetan and Xinjiang plan" launched by Zhejiang, Shanghai, Guangdong, Jiangsu, Shandong, Jiangxi, Hubei and other places successively go on an expedition. This year, the first batch of 4,000 newly-added teachers was sent to Tibet and Xinjiang, before the fall semester begins in 2018, they will be in their corresponding place. Plus the number of pairing-assistance teachers, a total of 5,500 teachers and normal school students who are in-post internship have been sent by the provinces and municipalities. Wang Dinghua, director of the department of teacher affairs of the Ministry of Education, says that teachers who have worked in Tibet and Xinjiang for one and a half years can give priority to the appraisal of higher-level professional titles, which is not occupy promotion quota and is not restricted by quota if they have the qualifications, pass the examination, and meet the educational standard.

China has intensified the efforts of training rural teachers at public expense. This year will attract 45,000 college graduates to teach in the countryside; expand the implementation of the special post plan, and 90,000 people will be recruited in 2018, an increase of 10,000 over last year; launch the silver age lecture program, the year of 2018 plans to recruit 1,800 retired outstanding teachers to teach in rural areas, and 10,000 retired outstanding teachers will be recruited by 2020; vigorously implement the national training program, and more than 1 million rural teachers in the central and western regions will be trained in 2018; vigorously implement the rural teacher living allowance policy, Since 2013, the central government has allocated 12.75 billion yuan that has benefited 1.3 million teachers in 80,000 schools; training and reward program of the rural outstanding young teachers will be launched the implemented and 300 people has been selected each year, each of whom will be rewarded 10,000 yuan for five consecutive years. [7]

\section{CONCLUSION}

The new generation of rural teachers has become a fresh force in the rural educational reform and a linker between the urban and rural worlds. After the baptism of higher education, they have brought new educational philosophies and new educational ideas to rural education. Their influence is not only reflected in the classroom teaching, but also in the construction of rural schools. Young rural teachers rush to primary rural schools across the country with modern urban atmosphere, digital culture, youthful dreams, and their ideals, thus bringing a new world to the education of rural children and the countryside.

Rural teachers are the core force in the development of rural education. The construction of rural teacher teams is on the one hand supplementing teachers and on the other hand retaining teachers. Today, when the rural revitalization strategy is being implemented, the rural teacher supplement is faced with many problems that need to be solved urgently. However, the government's promotion and the participation of social forces are fueling the hope of the supplement rural teachers and the development of rural education.

\section{REFERENCES}

[1] Survey: Rural teachers are the most special person in the process of educational modernization [2015-09-01]. China Education News Network http://www.jyb.cn/basc/xw/201509/t20150910_636572.html. (in Chinese)

[2] The situation of the development of national educational business in 2016

http://www.moe.gov.cn/jyb_sjzl/s5990/201711/t20171110 318862.html. (in Chinese)

[3] Li Chunmei, Liu Kexin. Half of the "special post" teachers recruited for failure [N]. Yili Daily (Han), 2006-08-24. (in Chinese)

[4] Zhu Qizhen, Tian Muye. From probation teachers to "new probation" teachers. Retrospect and reflection on the issues of rural teachers [J]. Journal of Educational Science of Hunan Normal University, 2014, (3): 93-99 (in Chinese)

[5] Yu Ziru. Whether the "gift packages" can retain rural teachers [EB/OL] (2015-09-09) [2017-02-16]. http://news.xinhuanet.com/politics/201509/09/c 128210309.htm. (in Chinese)

[6] Chaijiang. Rural teacher loss and supplementary strategies [J]. Contemporary Education and Culture, 2010, (5): 53-55. (in Chinese)

[7] Deepening the reform of the construction of teachers in an all-round way-how to become an excellent teachers in big countries. [2018-09-06]. The website of the Ministry of Education of the People's Republic of China.

http://www.moe.gov.cn/jyb_xwfb/s5147/201809/t20180906_347601.ht $\mathrm{ml}$ (in Chinese) 